\title{
Natural Selection for Genetic Variants in Sport: The Role of Y Chromosome Genes in Elite Female Athletes with 46,XY DSD
}

\author{
Malcolm A. Ferguson-Smith • L. Dawn Bavington
}

Published online: 27 August 2014

(c) Springer International Publishing Switzerland 2014

\begin{abstract}
At present, it is widely assumed that hyperandrogenism in female athletes confers an unfair competitive advantage. This view is perpetuated in current regulations governing eligibility of female athletes with hyperandrogenism to compete, which identify testosterone levels in the male range as the critical factor. Detailed evidence is presented here for the first time that genes for stature (and possibly other genes) on the $\mathrm{Y}$ chromosome are responsible for the increased frequency of 46,XY disorder of sex development (46,XY DSD) among elite female athletes identified by eligibility tests. In many cases, androgens are non-functional or, alternatively, absent and therefore testosterone cannot be responsible for their athletic success. Genetic variation has a major role in the selection of individuals for training and success in competition; however, this variation is not grounds for determining who should compete in athletic events. There is no convincing evidence to support the view that hyperandrogenism is associated with performance advantage in female athletes. Current time-consuming regulations may lead to the unwelcome resurgence of innuendo in the media and coercion of female athletes into accepting gonadectomy and other treatments to which they might otherwise not have been subjected. These regulations should be withdrawn on the grounds that they are not supported
\end{abstract}

M. A. Ferguson-Smith ( $\square)$

Department of Veterinary Medicine, University of Cambridge,

Madingley Road, Cambridge CB3 0ES, UK

e-mail:maf12@cam.ac.uk

\section{D. Bavington}

School of Physical Education, Sport and Exercise Sciences,

University of Otago, Union Place West,

Dunedin 9054, New Zealand

e-mail: lisa.bavington@otago.ac.nz scientifically, are discriminatory towards women and place some female athletes at risk of unnecessary and potentially harmful investigations. Improved understanding about genetic factors that lead to selection in sport should offer reassurance that women with hyperandrogenism possess no physical attribute relevant to athletic performance that is neither attainable, nor present in other women.

\section{Key Points}

$\mathrm{Y}$ genes for stature (and possibly other Y genes) are responsible for the increased frequency of $46, \mathrm{XY}$ DSD among elite female athletes identified by eligibility tests.

Hyperandrogenism is not associated with performance advantage in female athletes.

Governing bodies in sport should withdraw their regulations on hyperandrogenism.

\section{Introduction}

Endogenous androgenic hormones in the circulation of elite female athletes with disorders of sex development (DSD) are widely held to give them a competitive advantage. This view is perpetuated in current regulations governing the eligibility to compete in women's competition, which seeks to identify cases suspected of being affected by female hyperandrogenism $[1,2]$. The history of these regulations can be traced back to an unfounded suspicion 
that males on occasion may have masqueraded as female athletes at international events. Although the International Association of Athletics Federations (IAAF) and the International Olympic Committee (IOC) required female athletes to provide medical certificates for eligibility purposes beginning in 1946 and 1948, respectively [3], the decision to make formal regulations for femininity control took place in 1964. The IOC considered this together with doping controls at the Olympic Games in Tokyo and set up a Medical Commission to deal with both issues. Arrangements for gender verification, which were introduced at several international events in 1966, consisted of physical examinations that were deeply resented by athletes as being both demeaning and unacceptable. The IOC responded in 1968 by introducing the sex chromatin test that distinguishes the sex chromosome status of XX women from XY men. Sex chromatin continued to be used at all major international events until the Olympic Games in 1992 at Albertville and Barcelona, where DNA tests were used instead. DNA was used again at Lillehammer in 1994 and at Atlanta in 1996, but in view of the strong opposition from medical specialists, the IOC agreed in 1999 to suspend compulsory tests based on sex chromosomes at the 2000 Olympic Games in Sydney [4]. The history of these events is well documented in many publications [5-11].

It will be appreciated that failure to pass the sex test had devastating effects on the unsuspecting athletes. None had doubts about their femininity and the discovery that they were genetic males with $\mathrm{X}$ and $\mathrm{Y}$ chromosomes came as a severe shock. As part of their 1968 protocol, the IOC Medical Commission required the athletes to undergo chromosome analysis, gynaecological examination and hormone tests before determining whether or not they were eligible to compete. Although some would have received their femininity certificates after completing these investigations, others were so distressed that they chose to withdraw from competition without further evaluation. As a result a number have been prevented unjustly from competing and have suffered personal and sometimes public humiliation [12]. Additional sex discrimination is evident from the regulation that required all female athletes to sign a statement accepting the arrangements and absolving the organisers from responsibility should an athlete be debarred in error.

In a response made to the British Olympic Committee declining an invitation to undertake sex chromatin testing for the Commonwealth Games at Edinburgh in 1970, Ferguson-Smith observed that there was a greater probability of detecting an unsuspecting female with androgen insensitivity syndrome (AIS) than a male imposter [13]. Also, if female athletes found physical examination unacceptable, it would be wiser to drop gender verification as a criterion of eligibility than to use a wholly inappropriate test. The same view has been expressed by a number of medical geneticists and others [8-11], and has been fully substantiated by events up to the present.

Since formal tests for female eligibility were introduced in 1966, no man has been identified in a women's event at international competitions. Despite the unfairness of the tests, this could be regarded as a success for femininity control were it not for the allegation that a man was included in an Asian volleyball team at the Olympic Games at Munich in 1972. It is said that the unidentified man exchanged passports with a woman who took the sex chromatin test on his behalf [14]. No test is likely to detect such a determined imposter. While imposters have not been detected, a substantial number of female athletes with a presumptive $\mathrm{XY}$ sex chromosome complement have been identified by eligibility tests. These cases fall into the category of disorders of sex development (46,XY DSD), previously termed intersex [15]. They are rare in terms of a population frequency of less than 1:20,000 [10] but are relatively common among top class athletes, occurring in at least 1 in 421 female athletes. This informal estimate is based on data from 11,373 female athletes accessed through personal communication with colleagues involved in testing and from the summaries of results available after various international events (including one personally supervised) [11]. The estimate is confirmed in the official account of testing the 3,387 female athletes at the 1996 Olympic Games in Atlanta, where 1 in 423 failed gender verification [10]. These results seem to suggest that individuals with $46, \mathrm{XY}$ DSD have a competitive advantage over women with an XX sex chromosome complement who pass the eligibility tests. However, there is no evidence that these athletes possess any physical attribute relevant to athletic performance that is neither attainable nor present in 46,XX women. This view was held by the IAAF in 1992 [8] and is consistent with recent scholarship [16].

\section{Natural Selection for Genetic Variants: Stature and Athletic Performance}

It is worth considering the relationship between increased stature and performance in 46,XY DSD athletes who have been most often identified by eligibility testing. The majority of these cases have AIS, in which testosterone is non-functional, and therefore their performance cannot be due to testosterone. Other athletes with incomplete androgen insensitivity (IAIS), $5 \alpha$-reductase deficiency, and those who have undergone sex reassignment from male to female have been known to have had bilateral orchidectomy as part of their medical treatment well before entering competitive sport; for example, at the 1996 Olympic Games 
(see below) [10]. Their performance also cannot be attributed to testosterone. Further, athletes with IAIS appear to have no additional advantage over those with complete AIS.

It is well known from dose response studies in men that there is a relationship between supraphysiological doses of exogenous testosterone and muscle mass and strength [17, 18]. However, as far as we are aware, no such relationship between endogenous testosterone levels and muscle mass and strength has been established for women or, in particular, for female athletes. On the contrary, a recent study of hormone profiles in 693 post-competition elite athletes suggests that serum testosterone is not related to athletic performance in women [19]. Despite the lack of support for the supposed effect of testosterone, the new regulations on female hyperandrogenism that now replace the rules for gender verification perpetuate the view that testosterone levels are the critical factor [20, 21]. While the use of high doses of anabolic steroids has been shown to lead to performance enhancement in both male and female athletes, the regulation of these substances falls under anti-doping controls and is not relevant to the consideration of endogenous levels of testosterone in women [21, 22].

Ferguson-Smith has previously expressed the view that genes for increased stature on the $\mathrm{Y}$ chromosome, rather than the level of testosterone, may play a key role in the apparent competitive advantage of elite female athletes with 46XY, DSD [11]. Other less obvious Y sequences may also play a part, as regulatory sequences on the Y chromosome appear to increase the expression of some autosomal genes involved in male development [23]. XY men have greater lean body mass (LBM) than XX women [19] and this is likely to be the case in XY DSD female athletes. Strong evidence for height, which correlates with LBM (see [19]), is provided by the results of gender verification reported from the Centennial Olympic Games at Atlanta in 1996 [10]. Of the 3,387 female athletes competing at Atlanta, eight (1:423) were SRY (sex-determining region of the $\mathrm{Y}$ chromosome) positive (i.e., had presumptive 46,XY chromosomes) on DNA testing. Seven of the eight had AIS, complete in three and incomplete in four, and one case had $5 \alpha$ reductase deficiency. Bilateral gonadectomy had been performed in six of the eight and so testicular testosterone could not have led to any perceived advantages in performance. All eight athletes, including one with AIS and the other with IAIS whose testes were not removed, passed the clinical and laboratory investigations and were granted eligibility certificates. Of particular interest, the eight cases had heights ranging from 167 to $184 \mathrm{~cm}$ with a mean of $175 \mathrm{~cm}$, all close to the normal male range $(174.7 \mathrm{~cm}$, SD 6.7) but not outside the female range for height [4]. The athlete with $5 \alpha$-reductase deficiency was
$184 \mathrm{~cm}$ in height; others with the same condition are also known to be tall [24].

These findings are consistent with other evidence that the Y chromosome has genes for stature [25, 26]. For example, a group of 23 female patients with AIS from the general population are reported to have a mean height of $172.2 \mathrm{~cm}$ (SD 6.5) compared with normal females with a mean height of $162.2 \mathrm{~cm}$ (SD 6.0) [27]. In comparison, a series of 33 male patients with 46,XX testicular DSD have an average adult height of $166.4 \mathrm{~cm}$ (SD 7.4); i.e., within the female range. The short stature in the XX DSD males is evident despite the post-pubertal secretion of testicular androgens responsible for their masculinisation [25]. There is no suggestion that they have any particular athletic ability. Thus, in these DSD patients not selected for athletic ability, height is determined by genes on the Y chromosome and not by the action of androgens. There is additional strong evidence for stature genes on the $\mathrm{Y}$ chromosome in 31 individuals with the 47,XYY syndrome [28], where the double dose of $\mathrm{Y}$ chromosomes is associated with a mean height of $185 \mathrm{~cm}$ (SD 7.0). It is not known if 47,XYY cases have occurred among elite male athletes.

The evident association between height and the athletic performance of female 46,XY DSD athletes is best understood from the procedures that have evolved in the selection of young people for participation in competitive sport. It is natural that tallness is an advantage to the athlete in many events. Team sports such as basketball, netball and volleyball are notable examples where stature is especially important in relation to sports performance [29-31]. Potential athletes will be attracted to sports where they perceive themselves to have an innate advantage, such as height, over others. Likewise, sports coaches will encourage those with advantage in height, and will tend to select them for special training to improve their strengths and skills. Success in events at the club level can lead on to success at national level and eventually to international events including the Olympic Games.

Genetic variation is responsible for most phenotypic differences among athletes, involving both physical and neurological attributes, and these are modified by experience and by environmental factors including diet and physical training. This genetic variation helps to determine the ability of an athlete in a particular sport and is important in their selection. The genetic component in the case of sex segregation in sport seems largely provided by the $\mathrm{Y}$ chromosome. Also, in women, a double dose of genes on the $\mathrm{X}$ chromosome may contribute to female bodily habitus, and evidence for this has been reported from studies of children with sex chromosome DSD [32]. Genes on many other chromosomes are known to influence height; for example, those involved in Marfan syndrome 
[33]. Variation in many genes located throughout the genome (for example, the gene for angiotensin-converting enzyme) are now documented as contributing to sport performance, particularly in endurance events [34]. Nonetheless, these genetic factors are not singled out as important determinants in eligibility to compete. Evidence has also been presented regarding the importance of other genetic variations that may confer advantage in sport, but which are not subject to regulation [35-37].

It is not suggested here that athletes should be segregated in sport by any genetic factor, including genes controlling height, whether located on the $\mathrm{Y}$ or on any other chromosome. However, exceptions occur in boxing and weightlifting events, for example, where athletes are segregated into classes according to their weight; this is traditional and has not been questioned. It is likely that failure to recognise that height increases the chance that an athlete with 46,XY DSD will be positively selected for competition can be attributed to the decision by the IAAF and IOC, on the grounds of confidentiality, not to divulge details of those who had failed gender verification tests. A specific request for anonymous information about clinical findings in athletes (and the events in which they participated) who had failed femininity tests was made in the Report of the Monte Carlo Workshop convened by the IAAF in 1990 to give advice on changes in gender verification [11]. However, the IAAF and IOC Medical Commission ignored this request. The information could have reassured specialists in sports medicine and the athletics community that their previous anxieties about intersex and sex reversal were misplaced. DSD disorders could have been recognised as extreme examples of the genetic variation that underlies the selection of individuals for competition in all sports. It is hoped that the IOC Medical Commission will reconsider and release an analysis of any anonymous data they have not destroyed on past gender verification tests so that the conclusions presented here may be tested further. Certainly, no convincing evidence has ever been presented to support their assertion that hyperandrogenism is responsible for performance advantage in female athletes [20, 21].

\section{IAAF and IOC Regulations on Female Hyperandrogenism}

The regulations that were issued by the IAAF in 2011 [2] and the IOC in preparation for the 2012 Olympic Games in London $[1,38]$ represent a significant change to previous arrangements. The disorders subject to the new regulations are grouped under the heading of female hyperandrogenism, a term recently introduced to describe a syndrome in women characterised by hirsutism, acne, menstrual irregularity, various degrees of virilisation and subfertility [39].
The most common condition in this category is polycystic ovary syndrome, and this is said to be a frequent cause of menstrual dysfunction among female athletes $[40,41]$. The condition seems to be inherited as a simple dominant trait with variable expression, but whether the gene leads to a performance advantage in athletes is unknown. Other conditions such as 46,XY DSD, 46,XX DSD and androgenproducing tumours are also listed as subject to regulation. We are not aware of reports of elite athletes with congenital adrenal hyperplasia [42], and testing for this seems unsupported [37]. With regard to androgen-producing tumours, one case in an elite 14-year-old athlete with extremely elevated androgens is reported in which the removal of the tumour and reduction of hormone levels to normal was not followed by any significant decrease in her muscle strength or her athletic performance [43]. New IAAF rules have also been introduced to apply to postpubertal athletes who have undergone sex reassignment from male to female [44].

The IAAF regulations confirm that compulsory gender verification is no longer required. Instead, all females suspected to have hyperandrogenism will be evaluated by an initial clinical examination with blood and urine hormone levels or, alternatively, by a full examination at a specialist referral centre. Affected individuals are expected to present themselves for investigation, or be referred by a medical officer during a routine health check at national level, or during doping controls, or by a challenge from a medical officer during competition. The main criterion for a diagnosis of hyperandrogenism is a test result indicating that the total testosterone level is above the minimum acceptable male level (10 nmol/l) [2] and is functional [1, 2]. The results of the initial investigation are to be submitted on an anonymous basis to an Expert Panel who will decide whether or not the athlete has hyperandrogenism, and will make a recommendation as to the athlete's eligibility to compete.

The regulations state (incorrectly) that elevated androgen production has performance enhancing effects and that this requires regulation $[1,2]$. Therefore, to be allowed to complete, female athletes with testosterone levels above the minimum acceptable level must undergo treatment to reduce their level. Treatment implies orchidectomy or therapy with androgen inhibitors. We submit that it is unethical to pressurise athletes into accepting either of these measures. The only grounds for treatment are medical, such as the risk of gonadal cancer in $46, X Y$ DSD cases. In all cases, the athlete should be assisted to live in the gender of her choice. There are four medical conditions that are likely to require investigation under current regulations: IAIS, $5 \alpha$-reductase deficiency, ovotesticular DSD and postpubertal sex reassignment from male to female. In each 
of these four situations bilateral orchidectomy is usually required to allow the individual to live in the female gender and in most of the observed cases this has taken place before entering competition so that androgen levels are within acceptable levels. While it is accepted that exogenous testosterone is a banned substance under antidoping controls, hormone levels have no place in regulating female eligibility as endogenous testosterone is not a determinant of performance advantage. These current time-consuming regulations may also lead to unwelcome resurgence of innuendo in the media while athletes are temporarily suspended from competition [20] and to the coercion of female athletes into accepting gonadectomy and other treatments to which they might otherwise not have been subjected [16]. Our conclusions are supported by others who argue that these policies should be withdrawn on the grounds that they are not supported scientifically, are discriminatory towards women and place some female athletes at risk of unnecessary and potentially harmful investigations $[16,19-21,45-47]$.

\section{Conclusion}

It is evident that genetic variation plays a major role in the selection of individuals for training in athletics and in their success in competition. However, genetic variation is not grounds for determining who should compete in athletic events. The genetic component in the case of sex segregation in sport seems largely provided by the $\mathrm{Y}$ chromosome, yet governing bodies in sport have ignored the causal role of genetics in athletic performance. We find that there is no evidence to implicate testosterone and no rationale for any eligibility test based on female hyperandrogenism. Rather, tallness, whether determined by genes on the $\mathrm{Y}$ or any other chromosome, offers an example of an acceptable variable that contributes to athletic success in elite female athletes including those with 46,XY DSD. Athletes may still regard the current regulations as an important check against those who by virtue of their medical condition appear to have an unfair advantage. However, improved understanding about genetic factors that lead to selection in sport should offer reassurance that female athletes with hyperandrogenism do not possess any physical attribute relevant to athletic performance that is neither attainable, nor present in other women.

Acknowledgments No sources of funding were used to assist in the preparation of this article. Neither MAFS nor LDB have conflicts of interest that are directly relevant to the content of this review.

\section{References}

1. International Olympic Committee. IOC regulations on female hyperandrogenism. 2012. http://www.olympic.org.

2. International Association of Athletics Federations. IAAF regulations governing eligibility of females with hyperandrogenism to complete in women's competition. 2011. http://www.iaaf.org.

3. Heggie V. Testing sex and gender in sports; reinventing, reimagining and reconstructing histories. Endeavour. 2010;34:157-63.

4. Elsas LJ, Ljungqvist A, Ferguson-Smith MA, et al. Gender verification of female athletes. Genet Med Rep. 2000;2:249-54.

5. de la Chapelle A. The use and misuse of sex chromatin screening for "gender verification" of female athletes. JAMA. 1986;256:1920-3.

6. Simpson JL. Gender testing in the Olympics. JAMA. 1986;256:1938.

7. Ferguson-Smith MA, Ferris EA. Gender verification in sport: the need for change? Br J Sports Med. 1991;25:17-20.

8. Ljungqvist A, Simpson JL. Medical examination for health of all athletes replacing the need for gender verification in international sports. JAMA. 1992;267:150-2.

9. Simpson JL, Ljungqvist A, de la Chapelle A, et al. Gender verification in competitive sports. Sports Med. 1993;16:305-15.

10. Elsas LJ, Hayes RP, Muralidharan K. Genetic verification at the Centennial Olympic Games. J Med Assoc Ga. 1997;86:50-4.

11. Ferguson-Smith MA. Gender verification and the place of XY females in sport. In: Harries M, Williams C, Stanish WD, Micheli LJ, editors. Oxford Textbook of Sports Medicine. 2nd ed. Oxford: Oxford University Press; 1998. p. 355-365.

12. Martinez-Patino MJ. Personal account: a woman: tried and tested. Lancet. 2005;366(Sup 1.23):38-9.

13. Ferguson-Smith MA. Correspondence. Archives, Glasgow University; 1970.

14. Press releases of the IOC. Games of the XXth Olympiad. Olymp Rev. 1972;59:389-92.

15. Hughes IA, Houk C, Ahmed SF, et al. Consensus statement on management of intersex disorders. Arch Dis Child. 2006;91:554-63.

16. Jordan-Young R, Sönksen P, Karkazis K. Sex, health, and athletes. Br Med J. 2014. doi:10.1136/bmj.g2926.

17. Bhasin S, Storer TW, Berman N, et al. The effects of supraphysiologic doses of testosterone on muscle size and strength in normal men. N Eng J Med. 1996;335:1-7.

18. Bhasin S, Woodhouse L, Casaburi R, et al. Testosterone doseresponse relationships in healthy young men. Am J Physiol Endocrinol Metab. 2001;281:E1172-81.

19. Healy ML, Gibney J, Pentecost C, et al. Endocrine profiles in 693 elite athletes in the post-competition setting. Clin Endocrinol. 2014. doi:10.1111/cen.12445

20. Karkazis K, Jordan-Young R, Davis G, et al. Out of bounds? A critique of the new policies on hyperandrogenism in elite female athletes. Am J Bioeth. 2012;7:3-16.

21. Karkazis K, Jordan-Young R. The Harrison Bergeron Olympics. Am J Bioeth. 2013;13:66-9.

22. Sailors $P$, Teetzel S, Weaving C. The complexities of sport, gender, and drug testing. Am J Bioeth. 2012;7:23-5.

23. Clark AG. The vital Y chromosome. Nature. 2014;508:463-5.

24. Fénichel P, Paris F, Philibert P, et al. Molecular diagnosis of $5 \alpha-$ reductase deficiency in 4 elite young female athletes through hormonal screening for hyperandrogenism. J Clin Endocrin Metab. 2013. doi:10.1210/jc.2012-3893.

25. Ferguson-Smith MA, Cooke A, Affara NA, et al. Genotypephenotype correlations in XX males and their bearing on current theories of sex determination. Hum Genet. 1990;84:198-202. 
26. Ferguson-Smith MA. Genotype-phenotype correlations in individuals with disorders of sex determination and development including Turner's syndrome. Semin Dev Biol. 1991;2:265-76.

27. Ogata T, Matsuo N, The Y. Specific growth gene(s): how does it promote stature. J Med Genet. 1997;34:323-5.

28. Nielsen J. Klinefelter's syndrome and the XYY syndrome. Acta Psychiatr Scand Suppl. 1969;45:209.

29. Gualdi-Russo E, Zaccagni L. Somatotype, role, and performance in elite volleyball players. J Sports Med Phys Fitness. 2001;41:256-62.

30. Leone M, Lariviere G, Comtois AS. Discriminant analysis of anthropometric and biomotor variables among elite adolescent female athletes in four sports. J Sports Sci. 2002;20:443-9.

31. Baylos IA, Bergeles NK, Apostolidis NG, et al. Anthropometric, body composition and somatotype differences of Greek elite female basketball, volleyball and handball players. J Sports Med Phys Fitness. 2006;46:271-80.

32. Tanner JM, Prader A, Habich H, et al. Genes on the Y chromosome influencing rate of maturation in man. Lancet. 1959;22:141-4.

33. Reeser JC. Gender identity: is the playing field level? Br J Sports Med. 2005;39:695-9.

34. Ostrander EA, Huson HJ, Ostrander GK. Genetics of athletic performance. Ann Rev Genomics Hum Genet. 2009;10:407-29.

35. Sutherland M, Langer B, Wassersug R. Getting a leg up on the competition: the importance of osteology in elite athletics. Am J Bioeth. 2012;7:25-7.

36. Shani R, Yechiel M. Excellence, deviance, and gender: lessons from the XYY episode. Am J Bioeth. 2012;7:27-30.

37. Camporesi S, Maugeri P. Caster Semenya: sport, categories and the creative role of ethics. J Med Eth. 2010;36:378-9.

38. Vilain E, Sanchéz FJ. Athletes' bodies, sexed bodies-intersexuality in athletics. Nat Rev Endocrinol. 2012;8:198-9.
39. American Association of Clinical Endocrinologists. Medical guidelines for clinical practice for the diagnosis and treatment of hyperandrogenetic disorders. Endocr Pract. 2001;7:121-34.

40. Hagmar M, Berglund B, Brismar K, Hirschberg AL. Hyperandrogenism may explain reproductive dysfunction in Olympic athletes. Med Sci Sports Exerc. 2009;6:1241-8.

41. Bermon S, Ritzén M, Hirschberg AL, Murray TH. Are the new policies on hyperandrogenism in elite female athletes really out of bounds? Response to "Out of bounds a critique of the new policies on hyperandrogenism in elite female athletes". Am J Bioeth. 2013;13:63-5.

42. New MI. Inborn errors of adrenal steroidogenesis. Mol Cell Endocrinol. 2003;211:75-83.

43. Eliakim A, Cale-Benzoor M, Klinger-Cantor B, et al. A case study of virilizing adrenal tumour in an adolescent female elite tennis player: insight into the use of anabolic steroids in young athletes. J Strength Cond Res. 2011;25:46-50.

44. International Association of Athletics Federations. IAAF regulations governing eligibility of athletes who have undergone sex reassignment to complete in women's competition. 2011. http:// www.iaaf.org.

45. Viloria H, Martínez-Patino M. Reexamining rationales of "fairness": An athlete and insider's perspective on the new policies on hyperandrogenism in elite female athletes. Am J Bioeth. 2012;12:17-9.

46. Cooky C, Dworkin S. Policing the boundaries of sex: a critical examination of gender verification and the Caster Semenya controversy. J Sex Res. 2013;50:103-11.

47. Wonkam A, Fieggen K, Ramesar R. Beyond the Caster Semenya Controversy: the case of the use of genetics for gender testing in sports. J Genet Couns. 2010;19:545-8. 